\title{
Analysis of Edible Vegetable Oils by Infrared Absorption Spectrometry
}

\author{
Lei Shi, Zhilong Liu, Jinhong $\mathrm{Li}^{*}$ and Zhenxing Qin \\ Department of Physics, Taiyuan University of Science and Technology, Taiyuan 030024, China \\ ${ }^{*}$ Corresponding author
}

\begin{abstract}
In order to explore the more suitable conditions for using the edible vegetable oil in daily life, the peak position, peak shape, peak intensity and peak area detected by Fourier transform infrared spectroscopy (FTIR) of four different kinds of edible vegetable oils without heated and heated beyond the temperature of the smoke point have been measured. By analyzing the relative intensities of the peak high of the characteristic absorption peaks and the relative changes of the peak areas of the characteristic absorption peaks, it is found that the unsaturated fatty acids, trans fatty acids, the degree of unsaturation and other indicators of the oil heated beyond the temperature of the smoke point have been changed obviously. Aiming at index changes in the four kinds of edible vegetable oils, it is shown that both the relative contents of unsaturated fatty acids and the degree of unsaturation decrease at different extent for each oil, while the trans fatty acids increase at different extent for each oil. These changes reflect that the nutritional value of the vegetable oil has been greatly reduced and long-term ingestion will bring in adverse effect to human health when heated beyond the temperature of the smoke point. The obtained results are significant to correctly use the edible vegetable oil in everyday life.
\end{abstract}

Keywords-fourier transform infrared spectroscopy; vegetable oil; unsaturated fatty acids; trans fatty acids

\section{INTRODUCTION}

Edible oil safety becomes a hot point in modern society, which has attracted people's great concern. Edible vegetable oil is one of the essential fat foods in our daily life, which is made by the plant seeds after extraction, refining and processing. Meanwhile, the main materials of edible vegetable oil are soybeans, peanuts, sesames, rapeseed, corns, cottonseed, sunflowers, rice bran, flax seeds, castor beans, Palms, olives and so on. There are great differences in the price of edible vegetable oil because of the different varieties, producing areas and nutritional value. In life, many consumers often do not pay attention to the using temperature, so it is easy to exceed the temperature of its smoke point. The smoke point, which refers to the lowest temperature of the thermal decomposition of the sample or impurities continuously volatile visible to the naked eye when the oil is heated, is an evaluation index of the oil quality and one of sensory values during oil and non-triglyceride components heating process. In many cases, the edible vegetable oil is heated to a temperature above its smoke point. Not only the method of use is not inappropriate, but also repeated use results in increased oil viscosity, oil color deepening and peroxide value increased. Meanwhile, it produces some volatiles, aldehydes, ketones, lactones and other irritating odor of the materials, will give people a great harm to health. Therefore, the identification and analysis of various kinds of edible vegetable oil has increasingly become the focus of attention.

Oil is a kind of complex mixtures and analysis of oil involves many aspects related to the oil. With the rapid development of science and technology, oil analysis in depth and breadth has tremendous changes and oil analysis has entered a new level [1]. The recent development of Fourier transforms infrared spectroscopy (FTIR) is increasingly used in the food industry to promote the study of food analysis. In particular, online detection and rapid analysis can be combined with qualitative and quantitative methods such as discriminant analysis and cluster analysis, which has become a valuable measurement in the field of food [2-3]. With the advantages of fast, high efficiency, no pollution, no pretreatment, nondestructive analysis, online detection and multi-component simultaneous determination, infrared spectroscopy has been paid more and more attention [4-7]. The wave number range of infrared spectrum is about $11000 \sim 10 \mathrm{~cm}^{-1}$, which is divided into the following three areas: near infrared, middle infrared and far infrared. The mid-infrared region $\left(4000 \sim 400 \mathrm{~cm}^{-1}\right)$ is the region where the fundamental absorption bands of most organic and inorganic ions appear. Since the fundamental frequency vibration is the strongest absorption in the infrared spectrum, the region is the most suitable for qualitative or structural analysis. For the mid-infrared spectroscopy, it is the most mature and simple in the range of $4000 \sim 670 \mathrm{~cm}^{-1}$ and has accumulated a large amount of data in the area of information [8-9]. In summary, infrared spectroscopy is one of reliable methods for the detection edible vegetable oil.

The Fourier transform infrared spectroscopy was used to test the infrared spectra of four kinds of edible vegetable oils before and after heating, which are rapeseed oil, corn oil, olive oil and peanut oil. From the aspects of the relative change in the peak relative intensity of the characteristic absorption peak and the peak area, the contents of unsaturated fatty acids, trans fatty acids and the degree of unsaturation of four edible vegetable oils were analyzed and discussed.

\section{EXPERIMENT}

\section{A. Instruments and Reagents}

The WQF-510 Fourier transform infrared spectrometer of Beijing Rayleigh Analytical Instrument Company (The original Beijing second optical instrument factory), (The 
removable type liquid pool, $\mathrm{KBr}$ pellet), anhydrous ethanol, stainless steel pot, induction cooker.

\section{B. Experimental Conditions}

Detector measurement range of 4000 to $400 \mathrm{~cm}^{-1}$, resolution $1 \mathrm{~cm}^{-1}$, scanning frequency accumulation 32 times.

\section{Sample Preparation and Sources}

Four kinds of edible vegetable oils as follows: rapeseed oil, corn oil, olive oil and peanut oil, were selected as analysis samples. Sample number, production process, quality standards, such as the basic situation were shown in Table I.

TABLE I. BASIC INFORMATION OF FOUR KINDS OF EDIBLE VEGETABLE OIL

\begin{tabular}{|c|c|c|c|c|}
\hline & $\begin{array}{c}\text { The } \\
\text { product } \\
\text { standard }\end{array}$ & $\begin{array}{c}\text { Date of } \\
\text { production }\end{array}$ & $\begin{array}{c}\text { Food } \\
\text { origins }\end{array}$ & $\begin{array}{c}\text { Processing } \\
\text { technology }\end{array}$ \\
\hline Rapeseed oil & GB1536 & 2016.6 & Hunan & Press \\
\hline Corn oil & GB19111 & 2016.5 & Shandong & Press \\
\hline Olive oil & & 2016.4 & Spain & Press \\
\hline Peanut oil & GB1534 & 2016.4 & Shandong & Press \\
\hline
\end{tabular}

The four vegetable oils were heat-treated. The steps are as follows: First of all, fresh edible vegetable oil is taken appropriate. After that, pouring it into a dry and clean stainless steel pot, the oil is continuously heated (Heating the edible vegetable oils causes it to produce the massive fumes and the temperature value already achieved the smoke point.). Finally, the samples are obtained and tested by infrared spectroscopy after cooling.

\section{The Experimental Process}

First of all, Fourier transform infrared spectrometer is preheated stabilized, with the rubber burette to draw appropriate samples of edible vegetable oil (The heated sample is an oil sample of an edible vegetable oil of which heating temperature is to reach the smoke point.) in a clean $\mathrm{KBr}$ pellet. Then, the other salt pellet was pressed onto the $\mathrm{KBr}$ pellet so that the oil sample was evenly and vesicularly tiled between two $\mathrm{KBr}$ pellets. When $\mathrm{KBr}$ pellets were Carefully turned to make oil form a uniform liquid membrane, fixing and placing them in the infrared spectrometer sample holders, the infrared spectrometer was selected the parameters for the absorbance, resolution of $1 \mathrm{~cm}^{-1}$ and repetition scan 32 times. Under the design condition, the infrared absorption spectra of the samples without heating and heating were measured in turn and the spectra were processed to obtain a Fourier infrared absorption spectrum of the samples. After testing a sample, the $\mathrm{KBr}$ pellets were cleaned with absolute ethyl alcohol in order to wait for the next sample to be tested.

\section{RESULTS AND DISCUSSION}

Figure $\mathrm{I}$ is the absorption spectrum of the intensity maps that is rapeseed oil, corn oil, olive oil and peanut oil 4 kinds of edible vegetable oil without heating and heating to the smoke point. It can be seen from Figure I, the infrared absorption spectrum intensity maps of four kinds of edible vegetable oils before and after heating have similarities. In these infrared absorption spectrum intensities maps of different edible vegetable oils before and after heating, there are $\mathrm{O}-\mathrm{H}$ stretching vibration peak at $3471 \mathrm{~cm}^{-1}$, unsaturated C-H stretching vibration peak of carbon chain at $3007 \mathrm{~cm}^{-1}$, saturated carbon chain C-H stretching vibration peak at 2924 $\mathrm{cm}^{-1}$ and $2854 \mathrm{~cm}^{-1}, \mathrm{C}=\mathrm{O}$ stretching vibration peak at 1745 $\mathrm{cm}^{-1}$, the bending vibration peak of methylene at $1461 \mathrm{~cm}^{-1}$ and $1376 \mathrm{~cm}^{-1}$, the carbon skeleton vibration peak at $723 \mathrm{~cm}^{-1}$, the stretching vibration peak of $\mathrm{C}-\mathrm{O}$ in triglyceride at 1163 $\mathrm{cm}^{-1}$ and olefin reflector outside stretching vibration peaks at $967 \mathrm{~cm}^{-1}$. The spectrums of the peak position and peak shape are similar, thus the main components of different kinds of edible vegetable oils before and after heating are roughly the same.

\section{FIGURE I. ABSORPTION SPECTRUM INTENSITIES MAPS OF FOUR} EDIBLE VEGETABLE OILS BEFORE AND AFTER HEATING

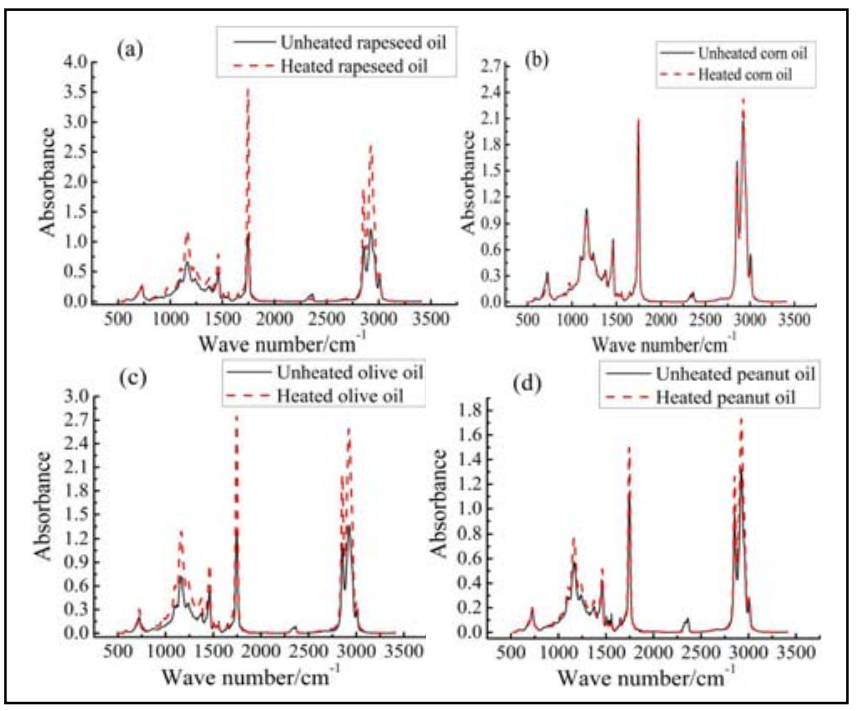

Table II shows the absorbance value of infrared spectrum characteristic peak when the rapeseed oil, corn oil, olive oil, peanut oil four kinds of edible vegetable oils without heating and heating to the smoke point. According to Table II, based on infrared absorption peak value of the characteristic peaks and the intensity of its own $\mathrm{C}=\mathrm{O}$ stretching vibration peak (wave number: $1747 \mathrm{~cm}^{-1}$ ), the relative intensities of the characteristic absorption peaks after unheating and heating to the smoke point are calculated. Table III shows the relative absorbance value of infrared spectrum characteristic peak when the rapeseed oil, corn oil, olive oil, peanut oil four kinds of edible vegetable oils without heating and heating to the smoke point. It can be seen from Table III, although the infrared absorption spectra of the edible oil are almost the same, the relative strength of their characteristic absorption peaks is different. Follows: C-H stretching vibrations of unsaturated carbon peaks at $3008 \mathrm{~cm}^{-1}$, indicate that their unsaturated fatty acids relative content decreased in different degrees when rapeseed oil, corn oil, olive oil, peanut oil 4 kinds of edible vegetable oils are heated to the smoke point. C$\mathrm{H}$ stretching vibrations of saturated carbon peaks at $2925 \mathrm{~cm}^{-1}$ and $2854 \mathrm{~cm}^{-1}$ have no significant change in the content of 4 kinds of edible vegetable oils. The relative content of the 
methylene bending vibration peaks at $1465 \mathrm{~cm}^{-1}$ and $1376 \mathrm{~cm}^{-1}$ were reduced to varying degrees in the four kinds of edible vegetable oils. The results showed that the carbon chain lengths of fatty acids in rapeseed oil, corn oil, olive oil and peanut oil were all shortened after heating.

TABLE II. KINDS OF EDIBLE OILS UNHEATED AND HEATED TO A SMOKE POINT OF CHARACTERISTICS OF INFRARED SPECTRA OF PEAK ABSORBANCE VALUE

\begin{tabular}{|c|c|c|c|c|c|c|c|c|}
\hline & $\begin{array}{c}\text { Unheated } \\
\text { rapeseed oil }\end{array}$ & $\begin{array}{c}\text { Heated } \\
\text { rapeseed oil }\end{array}$ & $\begin{array}{c}\text { Unheated } \\
\text { corn oil }\end{array}$ & $\begin{array}{c}\text { Heated corn } \\
\text { oil }\end{array}$ & $\begin{array}{c}\text { Unheated } \\
\text { olive oil }\end{array}$ & $\begin{array}{c}\text { Heated olive } \\
\text { oil }\end{array}$ & $\begin{array}{l}\text { Unheated } \\
\text { peanut oil }\end{array}$ & $\begin{array}{c}\text { Heated } \\
\text { peanut oil }\end{array}$ \\
\hline A723 & 0.247 & 0.311 & 0.344 & 0.260 & 0.204 & 0.304 & 0.180 & 0.198 \\
\hline A1163 & 0.665 & 1.192 & 1.072 & 1.001 & 0.724 & 1.292 & 0.571 & 0.765 \\
\hline A1376 & 0.264 & 0.389 & 0.366 & 0.341 & 0.252 & 0.440 & 0.209 & 0.259 \\
\hline A1461 & 0.481 & 0.794 & 0.722 & 0.659 & 0.528 & 0.872 & 0.422 & 0.516 \\
\hline A1745 & 1.130 & 3.545 & 2.045 & 2.115 & 1.286 & 2.748 & 1.136 & 1.501 \\
\hline A2854 & 0.924 & 1.889 & 1.612 & 1.575 & 1.143 & 2.005 & 0.955 & 1.264 \\
\hline A2924 & 1.208 & 2.597 & 2.079 & 2.328 & 1.362 & 2.585 & 1.326 & 1.732 \\
\hline A3008 & 0.402 & 0.472 & 0.549 & 0.384 & 0.295 & 0.411 & 0.263 & 0.280 \\
\hline
\end{tabular}

Note: A3008 said the number of waves to $3008 \mathrm{~cm}-1$ absorption peak absorbance values

TABLE III. KINDS OF EDIBLE OILS UNHEATED AND HEATED TO A SMOKE POINT OF CHARACTERISTICS OF INFRARED SPECTRA OF RELATIVE ABSORBANCE VALUE

\begin{tabular}{|l|c|c|c|c|c|c|c|c|}
\hline & $\begin{array}{c}\text { Unheated } \\
\text { rapeseed oil }\end{array}$ & $\begin{array}{c}\text { Heated } \\
\text { rapeseed oil }\end{array}$ & $\begin{array}{c}\text { Unheated } \\
\text { corn oil }\end{array}$ & $\begin{array}{c}\text { Heated corn } \\
\text { oil }\end{array}$ & $\begin{array}{c}\text { Unheated } \\
\text { olive oil }\end{array}$ & $\begin{array}{c}\text { Heated olive } \\
\text { oil }\end{array}$ & $\begin{array}{c}\text { Unheated } \\
\text { peanut oil }\end{array}$ & $\begin{array}{c}\text { Heated } \\
\text { peanut oil }\end{array}$ \\
\hline A723/A1747 & 0.219 & 0.088 & 0.168 & 0.123 & 0.159 & 0.111 & 0.158 \\
\hline A1164/A1747 & 0.588 & 0.336 & 0.524 & 0.473 & 0.563 & 0.470 & 0.503 \\
\hline A1376/A1747 & 0.234 & 0.110 & 0.179 & 0.161 & 0.196 & 0.160 & 0.184 \\
\hline A1465/A1747 & 0.426 & 0.224 & 0.353 & 0.312 & 0.411 & 0.317 & 0.371 \\
\hline A1747/A1747 & 1.000 & 1.000 & 1.000 & 1.000 & 1.000 & 1.000 & 1.000 \\
\hline A2854/A1747 & 0.818 & 0.533 & 0.788 & 0.745 & 0.889 & 0.344 \\
\hline A2925/A1747 & 1.069 & 0.733 & 1.017 & 1.101 & 1.059 & 0.941 & 0.841 \\
\hline A3008/A1747 & 0.356 & 0.133 & 0.268 & 0.182 & 0.229 & 0.150 \\
\hline
\end{tabular}

Note: The A3008/A1747 represents the relative wavenumber $3008 \mathrm{~cm}^{-1}$ absorption peak absorbance values.

In the infrared absorption spectrum of the four kinds of edible vegetable oils, $985 \mathrm{~cm}^{-1}$ peak area value (A985) represents the value of the conjugated fatty acid glyceride [10] value (Since most of the conjugated fatty acid glyceride in vegetable oil is anti-conjugated, anti-conjugated and anticonjugated.), the $960 \mathrm{~cm}^{-1}$ peak area (A960) represents the value of trans fatty acid glyceride content of single olefins, the peak area of $985 \mathrm{~cm}^{-1}$ and $960 \mathrm{~cm}^{-1}$ peak area (A985+A960) represents the total relative content of trans-fatty acid glyceride, and the peak area (A3008) of $3008 \mathrm{~cm}^{-1}$ represents the degree of unsaturation [11] (calculated using OMNIC software). Table IV shows the peak areas of infrared spectra of four kinds of edible vegetable oils, which are rapeseed oil, corn oil, olive oil and peanut oil without heating and heating to the smoke point. According to table IV, based on the peak area of the characteristic absorption peaks of the four kinds of edible vegetable oils and the peak area of $\mathrm{C}=\mathrm{O}$ stretching vibration peak (wave number: $1747 \mathrm{~cm}^{-1}$ ), the relative value of the sum of the areas of the absorption peaks of $985 \mathrm{~cm}^{-1}$ and $960 \mathrm{~cm}^{-1}$ and the peak area of the characteristic absorption peak of $3008 \mathrm{~cm}^{-1}$ were calculated. Table V shows the relative area of characteristic peak of infrared spectrum when the rapeseed oil, corn oil, olive oil, peanut oil four kinds of edible vegetable oils without heating and heating to the smoke point. According to table $\mathrm{V}$, the relative area of infrared spectral characteristic peaks when four kinds of edible vegetable oils is not heated and heated to the smoke point is different. After the heating process (Heating the edible vegetable oils causes it to produce the massive fumes and the temperature value already achieved the smoke point.), the relative content of trans fatty acids in each edible vegetable oil and the relative content of the unsaturation degree changed significantly. The relative content of trans fatty acids was increased to different extents and the degree of unsaturation was decreased in different degrees in the four kinds of edible vegetable oils.

TABLE IV. KINDS OF EDIBLE OILS UNHEATED AND HEATED TO A SMOKE POINT OF CHARACTERISTICS OF INFRARED SPECTRA OF PEAK AREAS

\begin{tabular}{|c|c|c|c|c|c|c|c|c|}
\hline & $\begin{array}{c}\text { Unheated } \\
\text { rapeseed oil }\end{array}$ & $\begin{array}{c}\text { Heated } \\
\text { rapeseed oil }\end{array}$ & $\begin{array}{c}\text { Unheated } \\
\text { corn oil }\end{array}$ & $\begin{array}{c}\text { Heated corn } \\
\text { oil }\end{array}$ & $\begin{array}{c}\text { Unheated } \\
\text { olive oil }\end{array}$ & $\begin{array}{c}\text { Heated } \\
\text { olive oil }\end{array}$ & $\begin{array}{c}\text { Unheated } \\
\text { peanut oil }\end{array}$ & $\begin{array}{c}\text { Heated } \\
\text { peanut oil }\end{array}$ \\
\hline A985+A960 & 4.520 & 11.898 & 7.007 & 11.554 & 3.347 & 11.361 & 4.816 & 7.023 \\
\hline A1747 & 40.088 & 70.555 & 63.853 & 65.307 & 42.922 & 85.374 & 35.783 & 47.545 \\
\hline A3008 & 14.393 & 18.145 & 18.393 & 14.500 & 10.560 & 15.303 & 9.210 & 10.264 \\
\hline
\end{tabular}


TABLE V. KINDS OF EDIBLE OILS UNHEATED AND HEATED TO SMOKE POINT OF CHARACTERISTICS OF INFRARED SPECTRA OF RELATIVE PEAK AREA

\begin{tabular}{|c|c|c|c|c|c|c|c|c|}
\hline & $\begin{array}{c}\text { Unheate } \\
\text { rapeseed } \\
\text { oil }\end{array}$ & $\begin{array}{c}\text { Heated } \\
\text { rapeseed oil }\end{array}$ & $\begin{array}{l}\text { Unheated } \\
\text { corn oil }\end{array}$ & $\begin{array}{c}\text { Heated corn } \\
\text { oil }\end{array}$ & $\begin{array}{l}\text { Unheated } \\
\text { olive oil }\end{array}$ & $\begin{array}{c}\text { Heated olive } \\
\text { oil }\end{array}$ & $\begin{array}{l}\text { Unheated } \\
\text { peanut oil }\end{array}$ & $\begin{array}{c}\text { Heated } \\
\text { peanut oil }\end{array}$ \\
\hline A985+A960/A1747 & 0.113 & 0.169 & 0.110 & 0.177 & 0.078 & 0.133 & 0.135 & 0.148 \\
\hline A1747/A1747 & 1.000 & 1.000 & 1.000 & 1.000 & 1.000 & 1.000 & 1.000 & 1.000 \\
\hline A3008/A1747 & 0.360 & 0.257 & 0.288 & 0.222 & 0.246 & 0.179 & 0.257 & 0.216 \\
\hline
\end{tabular}

\section{CONCLUSION}

In order to explore the more suitable conditions for the use of the edible vegetable oil in daily life, comparing the peak position, peak shape, peak intensity and peak area, which are measured by four different kinds of edible vegetable oils without heating and heating beyond the temperature of the smoke point (Heating edible vegetable oil generates a lot of smokes, the temperature has reached the smoke point at the same time.), is detected by Fourier transform infrared spectroscopy (FTIR). Besides, it was found that the main components of different kinds of edible vegetable oils were almost the same before and after heating. By analyzing the relative intensities of the peak high of the characteristic absorption peaks and the relative changes of the peak areas of the characteristic absorption peaks, it was found that the unsaturated fatty acids, trans fatty acids, the degree of unsaturation and other indicators of the oil heating beyond the temperature of the smoke point have had obviously changes. Aiming at index changes in 4 kinds of edible vegetable oils, the relative contents of unsaturated fatty acids decreased in different degrees, the trans fatty acids increased and the degree of unsaturation had different degree of declined. Unsaturated fatty acids are of extremely important significance to promote the human health and it has the regulation of blood lipids, cleaning up blood clots, immune regulation and other effects. When the relative contents of unsaturated fatty acids in edible vegetable oil are reduced, it is easy to cause the human body for the shortage of the unsaturated fatty acid intake and give birth to the body health source of tremendous dangers. The decrease of the unsaturation degree and the increase of trans fatty acids can cause the changes of the essence of polyunsaturated fatty acids, resulting in the reduction of the nutritional value of edible vegetable oil and the adverse effects on the health. Therefore, when people use the edible vegetable oil in our daily life, to control the heating process and to keep edible vegetable oil using temperature below the smoke point are very important for edible vegetable oil. These changes make the nutritional value of vegetable oil greatly reduced and long-term consumption will bring adverse effects to human health, so this study of how the healthy use of edible vegetable oil is of great significance. Hence, the temperature of edible vegetable oil is kept below the smoke point, and the heating process of the edible vegetable oil is controlled to avoid generating a large amount of soot, which is a very important practical significance for healthy and rational use of vegetable oil.

\section{ACKNOWLEDGMENT}

The authors are grateful to the University Student's Platform for Innovation and Entrepreneurship Training
Program of China (2016268, 201610109268), the University Student's Platform for Innovation and Entrepreneurship Training Key Program of Higher Education Institutions in Shanxi (2016268, 201610109268), and the National Natural Science Foundation of China (Grant Nos. 61405136 and 51502189).

\section{REFERENCES}

[1] J. Xu, P. Hou, Y. Wang, Z. Pan, "Determination of Component Contents of Blend Oil Based on Characteristics Peak Value Integration," Spectrosc. Spect. Anal. vol. A36, pp. 298-302, 2016.

[2] R. H. Wilson, H. S. Tapp. "Mid-infrared spectroscopy for food analysis: recent new applications and relevant developments in sample presentation methods,” Trend. Anal. Chem. vol. A18, pp. 85-86, 1999.

[3] G. Liu, W. Han, H. Jiang, "Study on Quality Identification of Olive Oil Based on Near Infrated Spectra,” Spectrosc. Spect. Anal. vol. A36, pp. 2798-2801, 2016.

[4] B. Zhang, L. Yuan, Q. Kong, W. Shen, C. Liu, "Rapid Discriminating Hogwash Oil and Edible Vegetable Oil Using Near Infrared Optical Fiber Spectrometer Technique,” Spectrosc. Spect. Anal. vol. A34, pp. 2723-2727, 2014.

[5] Qing Zhang, Cheng Liu, Zhi-Jian Sun, Xiao-Song Hu, Qun Shen, JiHong Wu. "Authentication of edible vegetable oils adulterated with used frying oil by Fourier Transform Infrared Spectroscopy,” Food Chemistry. vol. A132, pp. 1607 -1613, 2012.

[6] F. R. Voort, A. A. Ismail, J. Sedman, J. Dubois, T. Nicodemo. "The determination of peroxide value by fourier transform infrared spectroscopy,” J. Am. Oil Chem. Soc. vol. A71, pp. 921-926, 1994.

[7] M. E. S. Mirghani, Y.B. Che Man, S. Jinap, B. S. Baharin, J. Bakar. “A new method for determining aflatoxins in groundnut and groundnut cake using fourier transform infrared spectroscopy with attenuated total reflectance,” J. Am. Oil Chem. Soc. vol. A78, pp. 985-992, 2001.

[8] Q. Ding, L. Liu, Y. Wu, B. Li, O. Jie, “Authentication and Aduiteration Analysis of Sesame Oil by FTIR Spectroscopy,” Spectrosc. Spect. Anal. vol. A34, pp. 2690-2695, 2014.

[9] F. Liu, C. Yang, J. Xie, "Identification of Planting Area and Varieties of Rapeseeds by Infrared Spectroscopy Combing Stepwise Discriminatory Analysis,” Spectrosc. Spect. Anal. vol. A36, pp. 1363-1368, 2016.

[10] G. Picariello, A. Paduano, R. Sacchi, F. Addeo. "Maldi-tof mass spectrometry profiling of polar and nonpolar fractions in heated vegetable oils,” J. Agric. Food Chem. vol. A57, pp. 5391-5400, 2009

[11] L. Wang, J. Jin, S. Wang, X. Wang, Y. Tian, J. Chen. “A novel method for identification of illegal cooking oil(1): detection of three capsaicinoids with liquid chromatography-mass spectrometry,” Chin. J. Chromatogr. vol. A30, pp. 1094, 2012. 